\title{
Clinimetric Perspectives in Clinical Psychology and Psychiatry
}

\author{
Fiammetta Cosci ${ }^{a-c}$ \\ ${ }^{a}$ Department of Health Sciences, University of Florence, Florence, Italy; ${ }^{b}$ Clinical Pharmacopsychology Lab, \\ University of Florence, Florence, Italy; ' Department of Psychiatry and Neuropsychology, Maastricht University, \\ Maastricht, The Netherlands
}

Carrozzino et al. [1] outlined the major limitations of the psychometric model and provided a detailed description of the clinimetric properties that should be endorsed by patient-reported outcome measures (PROMs). In particular, homogeneity of components and unidimensionality, which are required by the psychometric model, may decrease sensitivity, a key clinimetric characteristic; responsiveness is only a part of the concept of sensitivity; clinical, predictive, and concurrent validity are suggested instead of convergent, divergent, content, structural, and criterion validity; sensibility is preferred to interpretability and feasibility. The criteria for clinimetric patient-reported outcome measures (CLIPROMs) suggested by Carrozzino et al. [1] represent the methodological framework to revise the armamentarium of existing PROMs and, eventually, create new indices, as it was the case for the Major Depression Inventory [2,3]. CLIPROM criteria may also favor the validation of observer-rated tools with the aim of increasing their clinical utility. An interesting example in this sense is the Hamilton Rating Scale for Depression [4], which has limited psychometric characteristics, but important clinimetric features that are enhanced or decreased according to the type of version [5].

Clinimetrics was introduced in clinical psychology and psychiatry in a special issue of Psychotherapy and Psychosomatics published in 2004; it was a tribute to Al- vain Feinstein, the father of clinical epidemiology and of clinimetrics. In the forum paper "Psychometric theory is an obstacle to the progress of clinical research," Fava et al. [6] clearly stated that psychometrics, being developed outside the clinical field, could not be automatically adapted to clinical psychology and psychiatry and described the importance of the clinimetric approach. Bech [7] observed that nonclinical investigators lack the solid clinical experience when they develop their scales and are therefore fascinated by the coefficients emerging from correlation analyses, often of statistical but not of clinical significance.

When Wright and Feinstein [8] provided an explanation for the disappointing performance that multi-item scales may present, they observed that homogeneity of components may obscure the ability to detect change, thus sensitivity [9]. On the contrary, when a new scale is developed based on clinimetric principles, essential variables that are sensitive to change and discrimination are included [10].

The inclusion of items in the construction of a scale should be guided by sensitivity. On the contrary, the customary psychometric goal is to achieve a unidimensional construct, in which the relatively homogeneous components all measure essentially the same phenomenon [11]. In this process, components that seem to be different and 
may be likely to detect change may be discarded. Similarly, in clinical research and practice, several highly redundant scales are often used under the misguided assumption that nothing will be missed. On the contrary, violation of the concept of incremental validity only leads to conflicting results. Incremental validity refers to the unique contribution or incremental increase in predictive power associated with the inclusion of a particular assessment procedure in the clinical decision process [12]. Each distinct aspect of psychological measurement should deliver a unique increase in information in order to qualify for inclusion [6].

In the psychometric model all items are weighed the same. This is at variance with clinical medicine, where major and minor symptoms are differentiated. Psychiatric nosography (i.e., DSM) still reflects the psychometric conceptual model: accordingly, severity is determined by the number of symptoms, not by their intensity or quality, to the same extent that a score in a depression rating scale depends on the number of symptoms that are scored as positive. It is likely, instead, that a given symptom may have a meaning in the presence of certain symptoms, and a different significance when it occurs together with other symptoms; thus, the relationship among numbers cannot be represented by a simple additive effect, but reciprocal interactions should be taken into account [13]. A patient with severe and pervasive depressed mood, incapacitating difficulty in concentrating, and severe late insomnia would not be diagnosed as suffering from a major depressive disorder according to the DSM, because it is the number of symptoms and not their severity that matters, despite the fact that clinicians might have the intuition of potential benefit from therapy [6]. If one presumes that the phenomenon to quantify is heterogeneous, then the sum of its single attributes contrasts with the basic principles of the logic [13]. Concordance is required between clinical coherence of symptoms and statistical coherence of symptoms, which is instead the essential feature of clinimetrics [7].

A subsequent paper authored by Fava et al. [14] in 2012 illustrated the clinical utility of the clinimetric approach in the assessment in psychiatry and clinical psychology. Nosography gives little consideration to the clinical process, that is how clinical judgment leading to clinical decisions is formulated. The main emphasis is given to the standardization of the assessment process by use of rating scales leading to diagnostic configuration [14] and, in most instances of diagnostic reasoning, the process ends with the identification of a disorder according to DSM criteria. A single assessment generates the prognos- tic and therapeutic judgments of the clinician. However, in 1967, Feinstein [15] devoted a monograph to an analysis of clinical reasoning that underlies medical evaluations, such as the appraisal of symptoms, signs, or timing of individual manifestations, and later proposed that the clinical reasoning should go through "transfer stations," where potential connections between presenting symptoms and pathophysiological process are drawn [16]. These stations are a pause for verification or change to another direction [16]. Transfer stations have been suggested as repeated assessments after each line of treatment has been completed in the framework of the sequential treatment model, an intensive, two-stage approach, which includes the use of one treatment for the acute phase of a mental illness and of another treatment (either pharmacological or nonpharmacological) to address the residual symptomatology that the other treatment was unable to affect [17].

The psychometric background of DSM has also implications in terms of comorbidity, which is exclusively framed in diagnostic labels by the current taxonomy. However, Feinstein [18], who introduced the term, outlined that comorbidity should be conceived as any additional "coexisting ailment" separate from the primary disease, even in the case this secondary phenomenon does not qualify as a disease per se. Thus, while DSM examines the interrelatedness of psychiatric symptoms and total psychopathological load, true comorbid conditions refer to having another disorder unrelated to the one of interest.

Fava et al. [14] remarked that such conceptualization may lend itself to a hierarchical organization of problematic areas and to focusing the attention to the longitudinal development of disorders (e.g., the primary/secondary distinction) [19]. The hierarchical organization of problematic areas has been reappraised in a clinimetric functional analysis in psychological assessment which is named macroanalysis [14, 20]. According to this model, a relationship between co-occurring syndromes and problems is established on the basis of where treatment should commence in the first place. Macroanalysis should be supplemented by microanalysis, a detailed analysis of specific symptoms (onset and course of the complaints, circumstances that worsen symptoms and consequences). Since comorbidity may vary from one illness to another and from one patient to another, clinimetric instruments may allow clinicians to treat syndromes as heterogeneous constructs which may entail different weights [6]. 
The longitudinal development of disorders can also be analyzed via the clinimetric approach of staging $[21,22]$, which characterizes each stage of mental illness and toward which possible development the patient is moving to. Thus, the observation of the patient is not cross-sectional (as in the DSM) but longitudinal, and the clinical phenomenon is observed in its evolution or involution. This demarcates major prognostic and therapeutic differences among patients who otherwise might seem to be deceptively similar since they share the same DSM diagnosis.

Accordingly, the availability of detailed and accurate clinical information also allows for subtyping mental disorders, the need for subtyping major depressive disorder, since this category is too broad to yield meaningful treatment implications, has been widely highlighted [14, 23]. Moreover, the clinimetric emphasis on global judgments $[24,25]$ may pave the way for building unitary concepts of mental disease that may overcome the limits of DSM comorbidity and its cross-sectional view. Tyrer et al. [26] remarked that what is shared by syndromes such as anxiety, panic, phobic disturbances, and irritability may be as important as the differences between them, and conditions that are apparently comorbid could be part of the same clinical syndrome. They argued that the combination of mixed anxiety and depressive disorders together with a certain type of abnormal personality constitute a single syndrome, the general neurotic syndrome [27].

There are several illustrations of the importance of a clinimetric perspective in these transdiagnostic domains which are complex and heterogeneous and, thus, cannot be captured by unidimensional tools as those proposed by psychometrics. One example is provided by allostatic overload, characterized by the presence of a source of distress in the form of recent life events and/or chronic stress which exceeds the individual's coping skills together with symptomatic manifestations encompassing psychological symptoms $[28,29]$ and its clinimetric translation in a diagnostic interview [28] and a self-rated questionnaire, the Psychosocial Index [30]. Another area is related to the concept of illness behavior, the ways in which individuals experience, perceive, evaluate, and respond to their health status [31]. It is a transdiagnostic core characterization, with multiple expressions, that is particularly important in psychosomatic medicine [32], which provides an explanatory model for clinical phenomena [33]. Illness behavior, because of its complexity, needs a clinimetric assessment, such as the Diagnostic Criteria for Psychosomatic Research [31] or the Illness Attitude Scale [34]. Mental pain is another transdiagnostic concept [35] that captures a feeling state characterized by emotional pain, emptiness, and internal perturbation. It may occur when an impending destruction of the person is perceived; it is at the core of the suicidal process. Mental pain also requires a clinimetric approach (e.g., the Mental Pain Questionnaire) [35-38] being complex and heterogeneous in addition to transdiagnostic.

Finally, an area of clinimetric application is concerned with psychological well-being. When a patient, in the longitudinal course of mood disturbances, no longer meets the threshold of a disorder, as assessed by diagnostic criteria or by cutoff points of rating scales, he/she is often labeled as euthymic. However, euthymia cannot be merely defined by negative terms (i.e., lack of symptoms or diagnosis) but should be based on the presence of specific positive features [39]. This introduces the need for a more comprehensive assessment of euthymia via clinimetric tools (e.g., the Euthymia Scale, the Clinical Interview for Euthymia) [37, 40-42]. Euthymia may play an important role in decreasing vulnerability to relapse, increasing the level of recovery, and modulating mood [43].

Personality factors are moderators or mediators which variously influence preclinical and clinical levels of illness from risk factors and vulnerability to maintenance of symptoms and recovery [44]. The psychometric distinction between state and trait entails difficulties in application with clinical populations [6]. Indeed, it has been shown to be misleading since state variables and psychological constructs traditionally conceived as trait dimensions may surprisingly display as sensitive to change [25], whereas constructs viewed as state dimensions may display unexpected stability throughout the longitudinal development of the disorder [22]. An example may be the artificial eudaimonic/hedonic dichotomy in psychological well-being and resilience and their modifications [45].

The information we previously mentioned adds to other customary domains of the clinical evaluation, such as background of alcohol and substance use, which can be assessed according to clinimetric principles as proposed by Cosci and Fava [46], general medical history, which can also take the advantage of psychosomatic assessment [47], and pharmacological history.

As what concerns psychotropic medications, the contribution of clinimetrics should be tracked at the level of assessment in the framework of iatrogenic comorbidity. Following Feinstein [18], also problematic areas due to the iatrogenic effects of treatment should be taken into account. Psychotropic drugs, particularly after long-term use, may increase the risk of experiencing additional psychopathological problems which do not necessarily sub- 
side with discontinuation or of modifying responsiveness to subsequent treatments and contribute to iatrogenic comorbidity [48]. This issue pertains to clinical pharmacopsychology, an area of clinical psychology that is concerned with the psychological effects of medications [49, 50]. A hot topic in this vein is withdrawal at decrease or discontinuation of psychotropic medication, particularly selective serotonin reuptake inhibitors (SSRIs), serotonin noradrenaline reuptake inhibitors (SNRIs), and antipsychotics [51]. Withdrawal syndromes can occur as part of the longitudinal development of a mental disorder in adults [51] as well as in adolescents [52]. Thus, they are in need of being known and assessed (for instance via clinimetric tools such as the Diagnostic Clinical Interview for Drug Withdrawal 1) [53], taken into account while proposing a treatment, hypothesizing a prognosis, and when the global functioning of patients is considered (for instance considering that withdrawal has been documented in the newborns of mothers under SSRI/venlafaxine) [54].

In brief, clinimetrics integrate clinical coherence with statistical coherence within the clinical framework [7]. Taking full advantage of clinimetric methods may greatly improve the clinical process in clinical psychology and in psychiatry, and clinimetric tools should be used more ex- tensively. As highlighted by Feinstein [55], if clinical research uses the wrong measures to assess efficacy, if subjects included in clinical trials fail to represent the patients who are encountered in clinical practice, if diagnostic tests are not thought through so that clinicians can apply them properly, and if cause and effect are confused in epidemiological studies, the results of science become merely academic.

\section{Conflict of Interest Statement}

The author is one of the inventors of the interview called "DID-W1 Diagnostic Clinical Interview for Drug Withdrawal 1 New Symptoms of SSRI and SNRI" whose copyright was deposited on November, 30, 2017, by the University of Florence.

\section{Funding Sources}

The author has no funding to declare.

\section{Author Contribution}

The author conceived and wrote the entire paper.

\section{References}

1 Carrozzino D, Patierno C, Guidi J, Berrocal C, Cao J, Charlson ME, et al. Clinimetric criteria for patient-reported outcome measures. Psychother Psychosom. 2021. https://doi.org/ 10.1159/000516599.

2 Bech P, Timmerby N, Martiny K, Lunde M, Soendergaard S. Psychometric evaluation of the Major Depression Inventory (MDI) as depression severity scale using the LEAD (Longitudinal Expert Assessment of All Data) as index of validity. BMC Psychiatry. 2015 Aug;15(1):190.

3 Carrozzino D, Christensen KS, Cosci F. Construct and criterion validity of patient-reported outcomes (PROs) for depression: a clinimetric comparison. J Affect Disord. 2021 Mar;283:30-5.

4 Hamilton M. A rating scale for depression. J Neurol Neurosurg Psychiatry. 1960 Feb;23(1):56-62.

5 Carrozzino D, Patierno C, Fava GA, Guidi J. The Hamilton Rating Scales for Depression: A Critical Review of Clinimetric Properties of Different Versions. Psychother Psychosom. 2020;89(3):133-50.

6 Fava GA, Ruini C, Rafanelli C. Psychometric theory is an obstacle to the progress of clinical research. Psychother Psychosom. 2004 MayJun;73(3):145-8.
7 Bech P. Modern psychometrics in clinimetrics: impact on clinical trials of antidepressants. Psychother Psychosom. 2004 MayJun;73(3):134-8.

8 Wright JG, Feinstein AR. A comparative contrast of clinimetric and psychometric methods for constructing indexes and rating scales. J Clin Epidemiol. 1992 Nov;45(11):1201-18.

9 Kellner R. The development of sensitive scales for research in therapeutics. In: Fava $M$, Rosenbaum JF, editors. Research designs and methods in psychiatry. Amsterdam: Elsevier; 1992. p. 213-22.

10 Fava GA, Carrozzino D, Lindberg L, Tomba E. The clinimetric approach to psychological assessment: A tribute to Per Bech, MD (19422018). Psychother Psychosom. 2018;87(6): 321-6.

11 Feinstein AR. Multi-item "instruments" vs Virginia Apgar's principles of clinimetrics. Arch Intern Med. 1999 Jan;159(2):125-8.

12 Sechrest L. Incremental validity: a recommendation. Educ Psychol Meas. 1963 Apr;23(1):153-8.
13 Faravelli C. Assessment of psychopathology. Psychother Psychosom. 2004 MayJun;73(3):139-41.

14 Fava GA, Rafanelli C, Tomba E. The clinical process in psychiatry: a clinimetric approach. J Clin Psychiatry. 2012 Feb;73(2):177-84.

15 Feinstein AR. Clinical judgment. Baltimore: Williams \& Wilkins; 1967.

16 Feinstein AR. An analysis of diagnostic reasoning. I. The domains and disorders of clinical macrobiology. Yale J Biol Med. 1973 Jun;46(3):212-32.

17 Guidi J, Fava GA. Sequential combination of pharmacotherapy and psychotherapy in major depressive disorder: a systematic review and meta-analysis. JAMA Psychiatry. 2021 Mar;78(3):261-9.

18 Feinstein AR. The pre-therapeutic classification of comorbidity in chronic disease. J Chronic Dis. 1970 Dec;23(7):455-68.

19 Robins E, Guze SB. Establishment of diagnostic validity in psychiatric illness: its application to schizophrenia. Am J Psychiatry. 1970 Jan;126(7):983-7.

20 Emmelkamp PM, Bouman TK, Scholing A. Anxiety disorders. Chichester: Wiley; 1993. p. 55-67. 
21 Fava GA, Kellner R. Staging: a neglected dimension in psychiatric classification. Acta Psychiatr Scand. 1993 Apr;87(4):225-30.

22 Cosci F, Fava GA. Staging of mental disorders: systematic review. Psychother Psychosom. 2013;82(1):20-34.

23 Bech P. Struggle for subtypes in primary and secondary depression and their mode-specific treatment or healing. Psychother Psychosom. 2010;79(6):331-8.

24 Feinstein AR. Clinimetrics. New Haven: Yale University Press; 1987. https://doi. org/10.2307/j.ctt1xp3vbc.

25 Fava GA, Tomba E, Sonino N. Clinimetrics: the science of clinical measurements. Int $\mathrm{J}$ Clin Pract. 2012 Jan;66(1):11-5.

26 Tyrer P, Seivewright N, Ferguson B, Tyrer J. The general neurotic syndrome: a coaxial diagnosis of anxiety, depression and personality disorder. Acta Psychiatr Scand. 1992 Mar;85(3):201-6.

27 Tyrer P, Tyrer H, Guo B. The general neurotic syndrome: a re-evaluation. Psychother Psychosom. 2016;85(4):193-7.

28 Fava GA, Guidi J, Semprini F, Tomba E, Sonino N. Clinical assessment of allostatic load and clinimetric criteria. Psychother Psychosom. 2010;79(5):280-4.

29 Guidi J, Lucente M, Sonino N, Fava GA. Allostatic load and its impact on health: a systematic review. Psychother Psychosom. 2021;90(1):11-27.

30 Sonino N, Fava GA. A simple instrument for assessing stress in clinical practice. Postgrad Med J. 1998 Jul;74(873):408-10.

31 Fava GA, Cosci F, Sonino N. Current psychosomatic practice. Psychother Psychosom. 2017;86(1):13-30.

32 Cosci F, Fava GA. The clinical inadequacy of the DSM-5 classification of somatic symptom and related disorders: an alternative trans-diagnostic model. CNS Spectr. 2016 Aug;21(4):310-7.

33 Cosci F, Guidi J. The role of illness behavior in the COVID-19 pandemic. Psychother Psychosom. 2021;90(3):156-9.
34 Sirri L, Grandi S, Fava GA. The Illness Attitude Scales. A clinimetric index for assessing hypochondriacal fears and beliefs. Psychother Psychosom. 2008;77(6):337-50.

35 Fava GA, Tomba E, Brakemeier EL, Carrozzino D, Cosci F, Eöry A, et al. Mental pain as a transdiagnostic patient-reported outcome measure. Psychother Psychosom. 2019;88 (6):341-9.

36 Cosci F, Svicher A, Mansueto G, Benemei S, Chiarugi A, De Cesaris F, et al. Mental pain and pain-proneness in patients with $\mathrm{mi}$ graine: results from the PAINMIG cohort study. CNS Spectr. 2020 Jun;25:1-10.

37 Guidi J, Piolanti A, Gostoli S, Schamong I, Brakemeier EL. Mental pain and euthymia as transdiagnostic clinimetric indices in primary care. Psychother Psychosom. 2019;88(4):252-

38 Svicher A, Romanazzo S, De Cesaris F, Benemei S, Geppetti P, Cosci F. Mental Pain Questionnaire: an item response theory analysis. J Affect Disord. 2019 Apr;249:226-33.

39 Fava GA, Bech P. The concept of euthymia. Psychother Psychosom. 2016;85(1):1-5.

40 Carrozzino D, Svicher A, Patierno C, Berrocal C, Cosci F. The Euthymia Scale: a clinimetric analysis. Psychother Psychosom. 2019;88 (2):119-21.

41 Fava GA, Guidi J. The pursuit of euthymia. World Psychiatry. 2020 Feb;19(1):40-50.

42 Zhang Y, Wang X, Carrozzino D, Yuan Y. Clinimetric properties of the Chinese version of the Euthymia Scale. Clin Psychol Psychother. 2021 Apr;IF 2.477.

43 Guidi J, Fava GA. The emerging role of euthymia in psychotherapy research and practice. Clin Psychol Rev. 2020 Dec;82:101941.

44 Cosci F. Assessment of personality in psychosomatic medicine: current concepts. Adv Psychosom Med. 2012;32:133-59.

45 Ryan RM, Deci EL. On happiness and human potentials: a review of research on hedonic and eudaimonic well-being. Annu Rev Psychol. 2001;52(1):141-66.
46 Cosci F, Fava GA. New clinical strategies of assessment of comorbidity associated with substance use disorders. Clin Psychol Rev. 2011 Apr;31(3):418-27.

47 Fava GA, Sonino N, Wise TN. Principles of psychosomatic assessment. Adv Psychosom Med. 2012;32:1-18.

48 Fava GA, Cosci F, Offidani E, Guidi J. Behavioral Toxicity Revisited: Iatrogenic Comorbidity in Psychiatric Evaluation and Treatment. J Clin Psychopharmacol. 2016 Dec;36(6):550-3.

49 Fava GA, Tomba E, Bech P. Clinical pharmacopsychology: conceptual foundations and emerging tasks. Psychother Psychosom. 2017;86(3):134-40.

50 Cosci F, Guidi J, Tomba E, Fava GA. The emerging role of clinical pharmacopsychology. Clin Psychol Eur. 2019;1(2):e32158.

51 Cosci F, Chouinard G. Acute and persistent withdrawal syndromes following discontinuation of psychotropic medications. Psychother Psychosom. 2020;89(5):283-306.

52 Offidani E, Fava GA, Tomba E, Baldessarini RJ. Excessive mood elevation and behavioral activation with antidepressant treatment of juvenile depressive and anxiety disorders: a systematic review. Psychother Psychosom. 2013;82(3):132-41

53 Cosci F, Chouinard G, Chouinard VA, Fava GA. The Diagnostic Clinical Interview for Drug Withdrawal 1 (DID-W1) - new symptoms of selective serotonin reuptake inhibitors (SSRI) or serotonin norepinephrine reuptake inhibitors (SNRI): inter-rater reliability. Riv Psichiatr. 2018 MarApr;53(2):95-9. Italian.

54 Wang J, Cosci F. SSRI-induced neonatal withdrawal syndrome following late in utero exposure to SSRIs: a systematic review and meta-analysis. Psychother Psychosom. Epub 2021 May 10. DOI: 10.1159/000516031.

55 Feinstein AR. Twentieth century paradigms that threaten both scientific and humane medicine in the twenty-first century. J Clin Epidemiol. 1996 Jun;49(6):615-7. 